\title{
Laparoscopic adrenalectomy: lateral transperitoneal versus posterior retroperitoneal approach - prospective randomized trial
}

\author{
Tomasz Kozłowski ${ }^{1}$, Barbara Choromanska ${ }^{1}$, Piotr Wojskowicz ${ }^{1}, K^{2}$ Kamil Astapczyk ${ }^{1}$, Jerzy Łukaszewicz ${ }^{1}$, \\ Dominika Rutkowski ${ }^{1}$, Jacek Dadan ${ }^{1}$, Alicja Rydzewska-Rosołowska ${ }^{2}$, Piotr Myśliwiec ${ }^{1}$ \\ ${ }^{1} 1^{\text {st }}$ Department of General and Endocrine Surgery, Medical University of Bialystok, Bialystok, Poland \\ ${ }^{2} 2^{\text {nd }}$ Department of Nephrology and Hypertension with Dialysis Unit, Medical University of Bialystok, Bialystok, Poland
}

Videosurgery Miniinv 2019; 14 (2): 160-169 DOI: https://doi.org/10.5114/wiitm.2019.84694

\begin{abstract}
Introduction: Laparoscopic adrenalectomy has become the gold standard of surgical treatment for benign adrenal masses. Two alternative surgical approaches are currently advocated: the lateral transperitoneal approach (LTA) and the posterior retroperitoneal approach (PRA). Several randomized trials have compared LTA to PRA, but most of them included small numbers of patients or had stringent inclusion criteria.

Aim: To compare clinical results of LTA and PRA endoscopic adrenalectomies for tumors $<8 \mathrm{~cm}$ with wide inclusion criteria.

Material and methods: We randomized 77 patients to either LTA $(n=33)$ or PRA $(n=44)$. The groups were comparable in terms of age, gender proportions, body mass index, tumor size, clinical and pathological diagnosis. We analyzed duration of surgery, intraoperative blood loss, postoperative pain, length of hospital stay and postoperative morbidity.

Results: The follow-up concerned $98.8 \%$ of patients and was on average $28(8-47)$ months long. There were no conversions. We identified significantly lower intensity of pain assessed $24 \mathrm{~h}$ after surgery in the PRA group (3.4 \pm 1$)$, as compared to LTA (4.2 \pm 1$)$, with lower prevalence of shoulder pain (2.3\% vs. 30.3\%, respectively). Postoperative hospital stay was shorter in the PRA $(1.14 \pm 0.4)$ than in the LTA $(1.36 \pm 0.5)$ group. Perioperative morbidity concerned 4 patients in each group with pain requiring oral analgesia $>7$ days.

Conclusions: To our knowledge this is the largest prospective randomized study comparing LTA to PRA. We demonstrated safety, efficacy and very low morbidity of both techniques. The PRA proved superior to LTA in terms of lower intensity of postoperative pain and shorter hospital stay.
\end{abstract}

Key words: laparoscopic adrenalectomy, retroperitoneal approach, randomized control study, pain, length of hospital stay, safety.

\section{Introduction}

Adrenal masses are among the most prevalent of all human tumors, accounting for approximately $3 \%$ in middle age and increasing to as much as $10 \%$ in the elderly [1-4]. A proportion of patients require surgical treatment due to hormonal activity or sus- picion of malignancy of adrenal mass [5]. Minimally invasive techniques have now been widely introduced in surgery, since 1992 also for treatment of adrenal tumors [6-8]. Laparoscopic adrenalectomy has become the gold standard of surgical treatment for benign adrenal masses. The main advantages of laparoscopic over open adrenalectomy are short-

\section{Address for correspondence}

Piotr Myśliwiec, $1^{\text {st }}$ Department of General and Endocrine Surgery, Medical University of Bialystok, Bialystok, Poland,

e-mail: piotr.a.mysliwiec@gmail.com 
er hospital stay, reduced postoperative pain, lower perioperative morbidity, especially lower infection rate, and faster recovery $[9,10]$.

Even though the first to have been described and still the most commonly used is lateral transperitoneal approach (LTA), its main alternative, posterior retroperitoneal approach (PRA), has been reported to be equally safe and effective [11-14]. The choice of the approach to adrenalectomy usually depends on the surgeon's experience, tumor size and anatomical location [15]. Increasing numbers of studies, systematic reviews and meta-analyses have identified the superiority of PRA over LTA in terms of shorter operative time, less postoperative pain, shorter hospital stay, lower morbidity and faster return to normal activity [16-18]. In the previous study we also reported apparent advantages of PRA over LTA, although this was a retrospective analysis and the groups were not matched [19].

The main objections to the randomized studies comparing LTA and PRA are selection bias, small number of patients, and bias related to differences in surgeons' experiences with the two methods of approach to endoscopic adrenalectomy [17]. Indeed, among the randomized studies, Fernandez-Cruz et al. [20] compared 10 to 11 operations, Mohammadi-Fallah et al. [21] compared 11 to 13 operations, and Rubinstein et al. [22] compared 25 to 32 patients, but he used the lateral retroperitoneal approach (currently almost abandoned), and not the posterior retroperitoneal approach. The best study so far compared 32 to 33 patients, but the exclusion criteria were rather extensive and comprised tumors $>7 \mathrm{~cm}$, diffuse peritonitis or major abdominal surgery in history, obesity $>40 \mathrm{~kg} / \mathrm{m}^{2}$, age $>80$ years and American Society of Anesthesiologists (ASA) stage IV [18].

\section{Aim}

The aim of this study was to compare prospectively clinical results of laparoscopic adrenalectomy randomized to either LTA or PRA. We opted for a study design with exclusions limited to the absolute minimum to keep the patients' flow as unbiased as possible.

\section{Material and methods}

\section{Trial design}

Between February 2015 and June 2018 all patients with adrenal tumors requiring adrenalectomy were prospectively assessed for eligibility in this study (Figure 1). The study was approved by the institutional ethical board.

The inclusion criterion was size of the adrenal tumor for planned unilateral adrenalectomy up to $8 \mathrm{~cm}$.

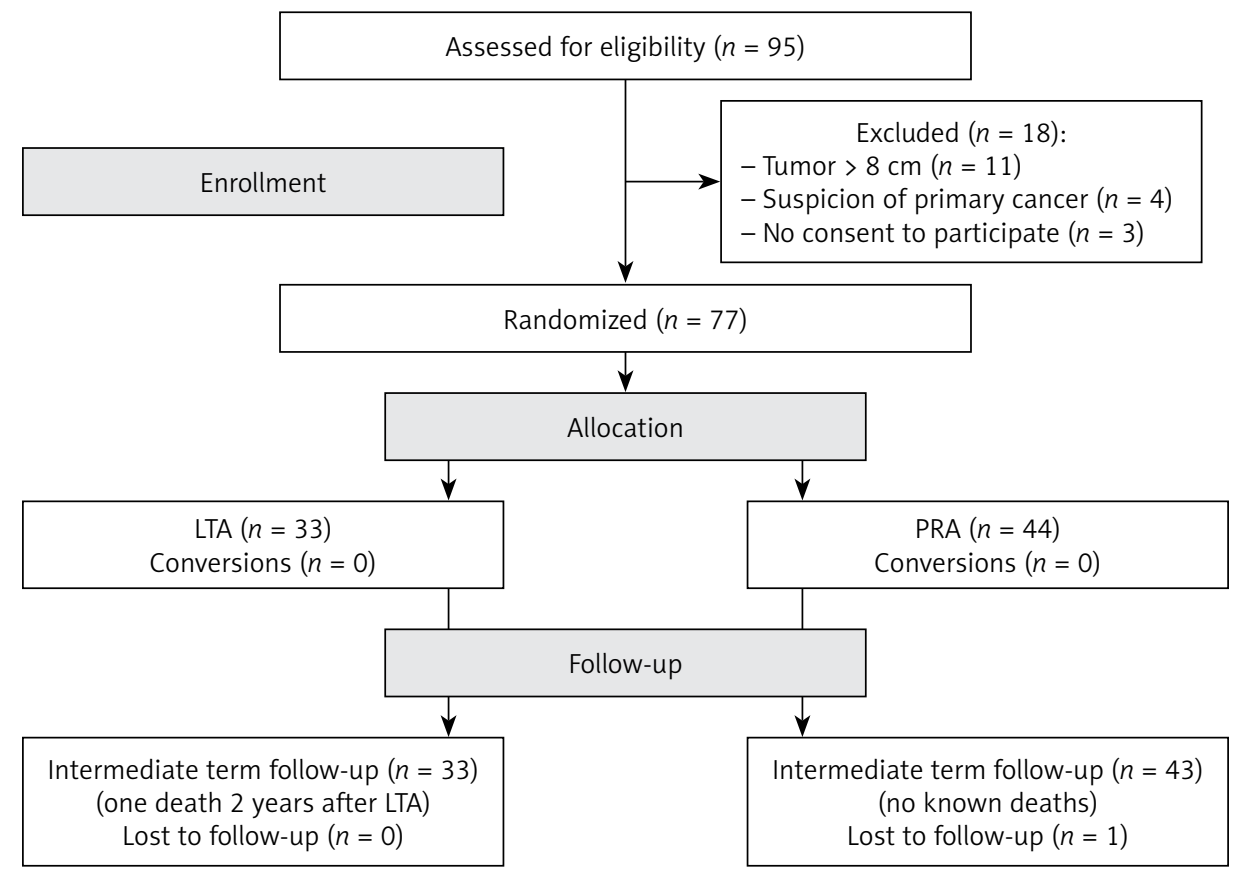

Figure 1. Flow diagram of the study 
Exclusion criteria were: tumors $>8 \mathrm{~cm}$, imaging features suggesting primary invasive malignant tumors and refusal of the patient to undergo randomization. The eligible patients were randomly assigned to undergo either LTA or PRA. To avoid any disturbance of free randomization, we did not use the computer option to balance the number of patients in the two groups. The sample size was calculated on the basis of the assumption that a $20 \%$ reduction in studied parameters should be clinically relevant.

\section{Perioperative workup}

In every case the adrenal tumor was evaluated using spiral computed tomography with contrast. Hormonal function assessment comprised urinary methoxycatecholamines, diurnal cortisol, adrenocorticotropic hormone (ACTH), dehydroepiandrosterone (DHEA), dexamethasone suppression test, serum aldosterone and renin activity, as well as ionogram. Positron emission tomography (PET) with 18-fluorodeoxyglucose (FDG) was used upon suspicion of metastatic adrenal gland tumors, to ascertain the clinical suspicion and to rule out dissemination of the disease. Only patients with a single focus in an adrenal gland were eligible for adrenalectomy. So were the patients with hormonally active tumors. Non-functioning tumors $>4 \mathrm{~cm}$ were also enrolled in the study due to substantial risk of malignancy in larger tumors.

In the case of pheochromocytoma pharmacological preparation before the surgery consisted of $\alpha$-adrenergic blockade 10-14 days before the surgery to avoid perioperative complications such as pheochro-

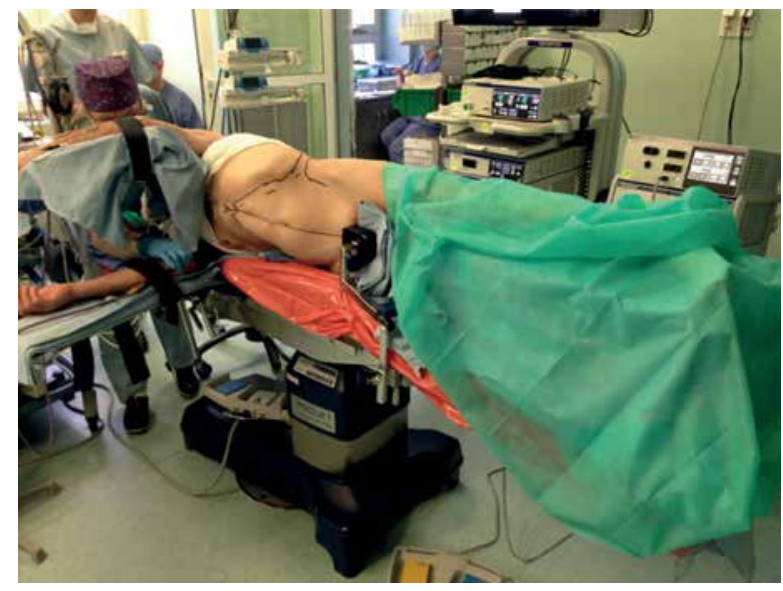

Photo 1. Patient positioning for left adrenalectomy using laparoscopic transperitoneal approach (photo by P. Mysliwiec) mocytoma paroxysm. Moreover, after $\alpha$-adrenergic blockade, $\beta$-adrenergic blockade was performed for at least 2 days prior to surgery. Patients with primary hyperaldosteronism were prepared with potassium-sparing diuretics. Electrolyte solutions were also used preoperatively. All patients were admitted a day before surgery and low molecular weight heparin (enoxaparin $40 \mathrm{mg}$ ) was injected subcutaneously $12 \mathrm{~h}$ preoperatively. A single dose of antibiotic (1000 mg cefazolin) was administered intravenously within 30 min before operations.

Patients with Cushing syndrome postoperatively received hydrocortisone in gradually diminishing doses according to serum cortisol concentrations and clinical assessment.

All patients gave their informed consent to participate in the study. All procedures were designed, conducted, and reported in compliance with the Declaration of Helsinki and were approved by the Ethics Committee of our institution (permission R-I002/66/2015), functioning according to the Guidelines for Good Clinical Practice.

\section{Interventions}

Unilateral total adrenalectomy was performed in all patients in this study. All the procedures were performed by one surgeon with 10 years of experience in laparoscopic adrenalectomies by the LTA and PRA approach.

Endoscopic adrenalectomies were performed as described by Barczyński et al. [18]. For LTA the patient was placed on the operating table in a lateral decubitus position on the side contralateral to the tumor, with moderate inclination at the level of the lower ribs (Photo 1). Pneumoperitoneum was created using a Veress needle for left adrenalectomy or the Hasson technique for right adrenalectomy and the pressure of $\mathrm{CO}_{2}$ was set at $12 \mathrm{~mm} \mathrm{Hg}$. The first, $10 \mathrm{~mm}$ trocar was inserted $2 \mathrm{~cm}$ below the rib arch in the anterior axillary line. Another $10 \mathrm{~mm}$ trocar and a $5 \mathrm{~mm}$ trocar were placed under the ribs at least $5 \mathrm{~cm}$ from the first one. In selected left-sided adrenalectomies and in all right-sided adrenalectomies an additional fourth trocar was used for retraction. The inspection of the peritoneal space was carried out using a $30^{\circ}$ laparoscope. After freeing adhesions, the spleen and splenic flexure of the colon or the liver were mobilized depending on the operated side. The left renal vein or inferior vena cava was identified. The main 
adrenal vein was ligated using a bipolar dissecting instrument and so were remaining vessels. In rare cases of vessels exceeding $7 \mathrm{~mm}$, polymer clips were used. When totally resected, the adrenal gland with surrounding fat was placed in an extraction bag and morcellated, once the edges of the bag were at least $2 \mathrm{~cm}$ outside. The operative field was controlled and any visible blood was aspirated. The area was flushed with warm $0.9 \%$ saline solution and aspirated. Wounds $10 \mathrm{~mm}$ or larger were sutured with a laparoscopic port site closure device. Skin sutures were applied.

For PRA the patient was placed in a prone position on a frame-shaped foam pad with lower limbs bent in the hip and knee joints (Photo 2). The procedure began with a skin incision at the tip of the $12^{\text {th }}$ rib and blunt penetration of the retroperitoneal space. Three trocars with diameters of 5, 10 and $12 \mathrm{~mm}$ were introduced into the retroperitoneal space. $\mathrm{CO}_{2}$ was insufflated to reach the pressure of $25 \mathrm{~mm} \mathrm{Hg}$. Similarly to LTA, PRA was carried out using a $30^{\circ}$ laparoscope. After penetrating Gerota's fascia, the upper pole of the kidney was identified. Further steps were similar to LTA.

In all patients, the skin and subfascial space were instilled with $10 \mathrm{ml}$ of $0.5 \%$ bupivacaine solution prior to skin incisions - for postoperative analgesia. No drains were used.

\section{Outcomes and follow-up}

We assessed the duration of the operative procedure from skin incision to skin suturing, conversion rate, intraoperative blood loss, postoperative pain intensity, duration and need for analgesics, length of hospital stay and postoperative morbidity. We analyzed age and gender of the patients, body mass, height, body mass index (BMI), hormonal, clinical and pathological diagnosis, operative time, intensity and duration of postoperative pain, intraoperative blood loss, length of hospital stay and complications. The pain was assessed in the morning of the first postoperative day using a visual analog scale (VAS) ranging from 0 for no pain, to 10 for maximal pain.

The patients were followed up postoperatively in the Outpatients' Department after 10, 30 days and at the end of the follow-up period. The patients were checked for pain intensity, need for analgesia, wound-related and overall complications.

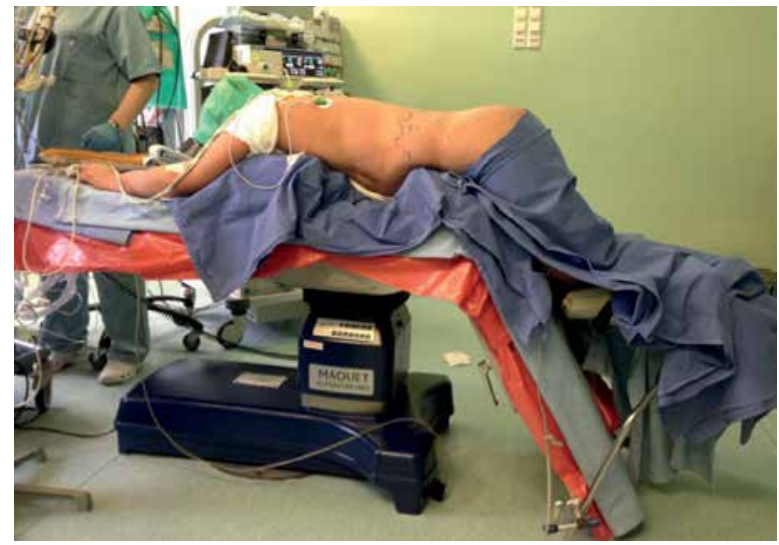

Photo 2. Patient positioning for left adrenalectomy using posterior retroperitoneal approach (photo by P. Mysliwiec)

\section{Statistical analysis}

Statistica 13 for Windows (StatSoft, Krakow, Poland) software was used. Distribution of data was checked with the Shapiro-Wilk test. Kruskal-Wallis ANOVA was used for comparing multiple independent groups and the Mann-Whitney test for comparing two independent samples. For dependent variables, the Wilcoxon test was used. Correlations were assessed using the Spearman test. For selected calculations comparing prevalence of analyzed features, the $\chi^{2}$ test was used. The value of $p<0.05$ was considered significant.

\section{Results}

After the exclusion of 18 patients from the 95 assessed for eligibility, the study group consisted of 77 patients with adrenal tumors: 33 were randomized to LTA and 44 to PRA (Figure 1). There were no significant differences between the two groups in terms of age, gender distribution, tumor size, location, hormonal or pathological diagnosis (Table I).

Even though operative time tended to be shorter for PRA as compared to LTA, the difference did not reach statistical significance (Table II, Figure 2 A). There was a trend for longer operative time in patients with metastases, pheochromocytoma and Cushing syndrome, as compared to Conn syndrome or incidentaloma (Figure 2 B). Blood loss was measurable only in a minority of the studied patients, with the mean of $20.6 \pm 15 \mathrm{ml}$ for LTA and $7 \pm 5 \mathrm{ml}$ (Table II) (difference not significant). No patients needed blood transfusions. 
After PRA patients reported less postoperative pain assessed at day 1 , as compared to LTA ( $p<$ 0.05) (Table II, Figure 3 A). The subset of patients with predominant shoulder pain was $30.3 \%$ in LTA group $(n=10)$ and only 1 patient in the PRA group $(2.3 \%)(p<0.05)$.

Table I. Patients' characteristics

\begin{tabular}{|c|c|c|c|}
\hline Parameter & $\operatorname{LTA}(n=33)$ & PRA $(n=44)$ & $P$-value \\
\hline Age [years]: & & & NS \\
\hline Mean \pm SD & $61.2 \pm 8.3$ & $59.3 \pm 10.2$ & \\
\hline Min.-max. & $44-84$ & $32-81$ & \\
\hline Gender: & & & NS \\
\hline Male & $13(39 \%)$ & $21(48 \%)$ & \\
\hline Female & $20(61 \%)$ & $23(52 \%)$ & \\
\hline $\begin{array}{l}\text { BMl, mean } \pm \text { SD } \\
{\left[\mathrm{kg} / \mathrm{m}^{2}\right]}\end{array}$ & $30.1 \pm 6$ & $29.1 \pm 5.2$ & NS \\
\hline $\begin{array}{l}\text { ASA, median } \\
\text { (min.--max.) }\end{array}$ & $3(2-4)$ & $3(2-4)$ & NS \\
\hline $\begin{array}{l}\text { Tumor size, median } \\
\text { (min.-max.) }\end{array}$ & $4.1(1.5-7.5)$ & $4.0(0.8-7.5)$ & NS \\
\hline Location: & & & NS \\
\hline Right side & $11(33 \%)$ & $18(40 \%)$ & \\
\hline Left side & $22(67 \%)$ & $26(60 \%)$ & \\
\hline Hormonal diagnosis: & & & NS \\
\hline Pheochromocytoma & $4(12 \%)$ & $9(20 \%)$ & \\
\hline Cushing's disease & $5(15 \%)$ & $3(7 \%)$ & \\
\hline Conn's disease & $2(6 \%)$ & $4(9 \%)$ & \\
\hline $\begin{array}{l}\text { Nonfunctioning } \\
\text { tumor }\end{array}$ & $22(67 \%)$ & $28(64 \%)$ & \\
\hline Pathological diagnosis: & & & NS \\
\hline Pheochromocytoma & $2(6 \%)$ & $5(11 \%)$ & \\
\hline Adenoma & $27(82 \%)$ & $31(70 \%)$ & \\
\hline Nodular hyperplasia & $1(3 \%)$ & $2(5 \%)$ & \\
\hline Myelolipoma & $1(3 \%)$ & $1(2.3 \%)$ & \\
\hline Ganglioneuroma & $1(3 \%)$ & $1(2.3 \%)$ & \\
\hline Cancer metastasis & $1(3 \%)$ & $3(7 \%)$ & \\
\hline Lymphangioma & $0(0 \%)$ & $1(2.3 \%)$ & \\
\hline
\end{tabular}

LTA - lateral transperitoneal approach, PRA - posterior retroperitoneal approach, SD - standard deviation, min.-max. - full range (minimum - maximum), NS - not significant, BMI - body mass index, ASA - operative risk according to American Society of Anesthesiologists.
After division of the patients into subgroups for left or right-sided LTA and left or right-sided PRA, the group of subjects after right-sided LTA had 1.5 times more pain than right-sided PRA $(p<0.01)$ and the left-sided PRA had 30\% more pain than right-sided PRA $(p<0.05)$ (Figure 3 B). When analyzing further the postoperative period, we found that after discharge $60.6 \%$ of patients after LTA and $63.8 \%$ after PRA needed no medication for pain (difference not significant) (Figure 4).

Postoperative hospital stay was significantly longer $(+19.3 \%)$ after LTA as compared to PRA $(p<0.05)$ (Table II, Figure $5 \mathrm{~A}$ ). After subgroup analysis into left- and right-sided operations, the patients after left-sided LTA had the longest hospital stay, which was significantly longer (+24.3\%) than after left-sided PRA $(p<0.05)$ (Figure 5 B).

Postoperative follow-up was similar in both LTA and PRA groups and averaged 28 months. The only type of 30-day morbidity observed in this study was postoperative pain lasting longer than 7 days, present in 4 patients from each group (Table II) and classified as grade I Complication, according to Dindo et al. [23]. One patient with class II obesity in the PRA group suffered from recurrence of previous low back pain, due to degenerative spine disease. In all other patients maximal pain duration was one month.

One 57-year-old patient required angioplasty with 4 stents due to unstable coronary disease 3 months after LTA. There was one death due to myocardial infarction 2 years after LTA, performed in an 82-yearold woman with cortical adenoma $7.2 \times 6 \mathrm{~cm}$. Three patients required long-term hydrocortisone supplementation ( 2 operated on for Cushing syndrome: 43 months after LTA and 20 months after PRA; and 1 operated on for Conn syndrome -44 months after LTA).

\section{Discussion}

To our knowledge this is the largest published prospective randomized study comparing LTA and PRA laparoscopic adrenalectomies, performed by one surgeon with comparable experience in both methods of adrenalectomy, well beyond the learning curve. The study has larger inclusion criteria than any other before, comprising morbidly obese patients (the highest BMI was $43.3 \mathrm{~kg} / \mathrm{m}^{2}$ ), tumors up to $8 \mathrm{~cm}$ in diameter, and metastatic tumors. The completeness of follow-up was $98.7 \%$, with only one patient lost to follow-up (1.3\%). 
Table II. Operative outcomes of laparoscopic adrenalectomies $(n=77)$

\begin{tabular}{|c|c|c|c|}
\hline Parameter & $\operatorname{LTA}(n=33)$ & $\operatorname{PRA}(n=44)$ & $P$-value \\
\hline Operative time, median (min.-max.) [min] & $70(30-140)$ & $65(30-140)$ & NS \\
\hline Blood loss, mean \pm SEM $[\mathrm{ml}]$ & $20.6 \pm 15$ & $7 \pm 4.8$ & NS \\
\hline Postoperative pain at day 1 [VAS] & $4.2 \pm 1$ & $3.4 \pm 1$ & $<0.05$ \\
\hline Postoperative hospital stay, mean \pm SD [days] & $1.36 \pm 0.5$ & $1.14 \pm 0.4$ & $<0.05$ \\
\hline Follow-up, mean \pm SD [months] & $28 \pm 13$ & $28 \pm 12$ & NS \\
\hline Conversions & 0 & 0 & \\
\hline 30-day complications (according to Dindo): & $4(12 \%)$ & $4(9 \%)$ & NS \\
\hline$a^{a}$ & $4^{\mathrm{a}}(12 \%)$ & $4^{b}(9 \%)$ & \\
\hline$\|$ & 0 & 0 & \\
\hline III & 0 & 0 & \\
\hline IV & 0 & 0 & \\
\hline V & 0 & 0 & \\
\hline
\end{tabular}

LTA - lateral transperitoneal approach, PRA - posterior retroperitoneal approach, min.-max. - full range (minimum - maximum), NS - not significant, SEM - standard error of measurement, VAS - visual analog scale (from 1 - minimal to 10 - maximal), SD - standard deviation. Complications within 30 days after the operation according to Dindo et al. [23]. a Pain lasting longer than 7 days; ${ }^{b} 1$ of 4 patients with pain lasting longer then 7 days (BMI = $\left.36.8 \mathrm{~kg} / \mathrm{m}^{2}\right)$ suffered from recurrence of previous low back pain due to degenerative spine disease; in all other patients maximal pain duration was 1 month.

A

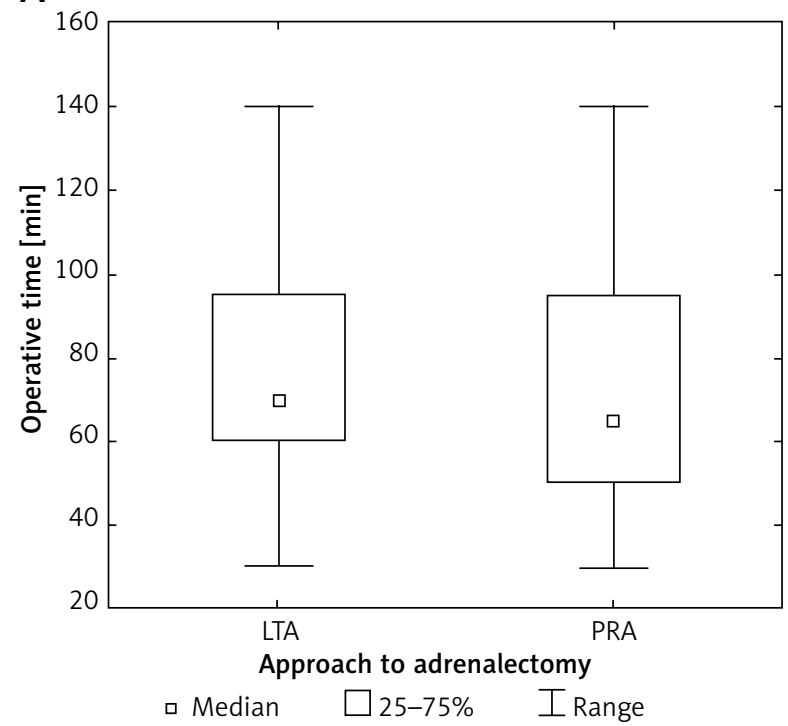

B

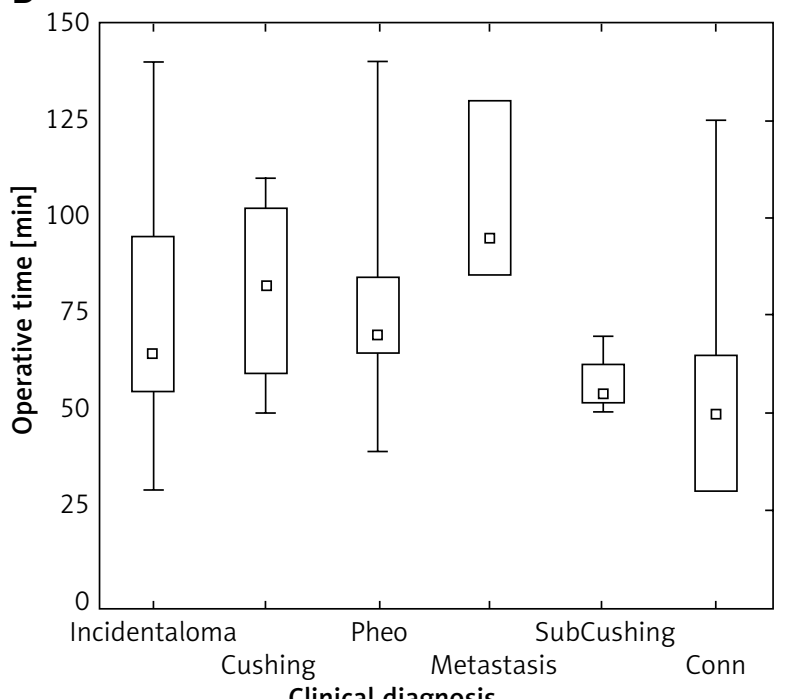

- Median $\square 25-75 \% \quad$ IRange

Figure 2. A - Adrenalectomy duration according to endoscopic approach. B - Adrenalectomy duration according to clinical diagnosis

LTA - lateral transperitoneal approach, PRA - posterior retroperitoneal approach. Incidentaloma - patients with nonfunctioning tumors without malignancy features or history; Cushing - patients with clinical and hormonal abnormalities typical for Cushing syndrome; pheo - patients with clinical or hormonal abnormalities typical for pheochromocytoma; metastasis - patients with nonfunctioning tumors with malignancy features and history; SubCushing - patients with mild hormonal abnormalities typical for subclinical Cushing syndrome; Conn - patients with clinical, hormonal and electrolytic abnormalities typical for Conn syndrome. Range - minimum - maximum. Difference not significant.

The present study showed that both approaches to endoscopic adrenalectomy are equally safe end effective. There were no conversions and periopera- tive morbidity included only pain requiring oral analgesics longer than 7 days (12.1\% in LTA and $9.3 \%$ in PRA group) (Figure 4). 
A

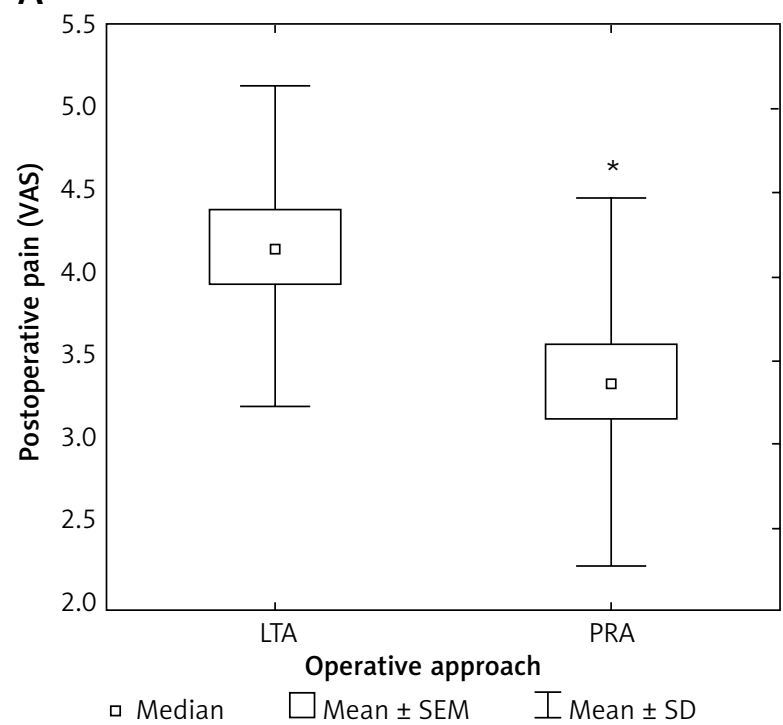

B

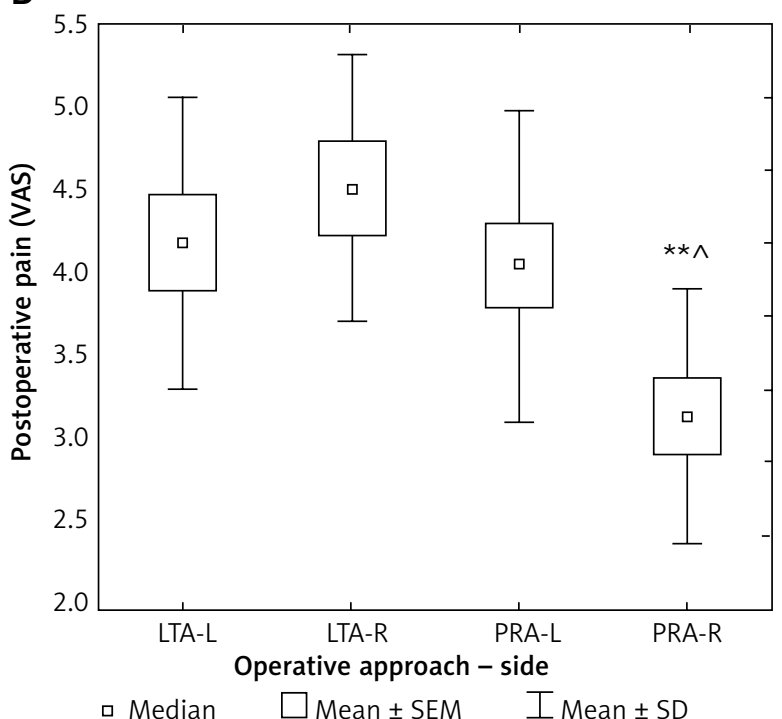

Figure 3. A - Postoperative pain at day 1 according to laparoscopic approach. B - Postoperative pain at day 1 according to laparoscopic approach and side of adrenalectomy

VAS - visual analog scale (from 0 - no pain, to 10 - maximal). LTA - lateral transperitoneal approach, PRA - posterior retroperitoneal approach, $S E M$ - standard error of measurement, SD - standard deviation; ${ }^{*} p<0.05$. VAS - visual analog scale (from 0 - no pain, to $10-$ maximal), LTA-L - left adrenalectomy by lateral transperitoneal approach, $L T A-R$ - right adrenalectomy by lateral transperitoneal approach, PRA- $L-l e f t$ adrenalectomy by posterior retroperitoneal approach, $P R A-R$ - right adrenalectomy by posterior retroperitoneal approach. SEM - standard error of measurement; $S D$ - standard deviation; comparison to LTA-R: ${ }^{* *} p<0.01$; comparison to PRA-L: ${ }^{\wedge} p<0.05$.

There was no clear correlation between the duration of adrenalectomy and the size of the tumor, even though operative time tended to be longer for tumor metastases, pheochromocytoma and Cushing syndrome (Figures 2 A, B). In 2 patients with PRA with the longest operative times (140 and $125 \mathrm{~min}$ ) we encountered indurated perirenal fat, making dissection extremely difficult. Another reason why we did not find a difference in time of surgery between LTA and PRA groups could be inclusion of patients with morbid obesity and metastases to the adrenal gland. Even though it might seem controversial
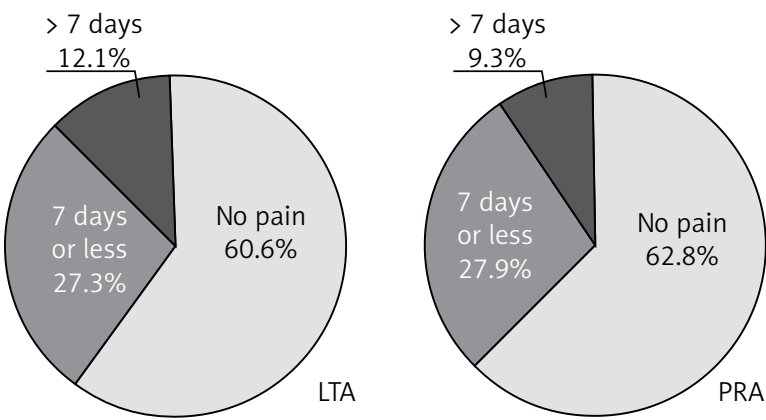

Figure 4. Prevalence of pain requiring oral analgesics after discharge from hospital

LTA - lateral transperitoneal approach, PRA - posterior retroperitoneal approach. whether metastases should be operated on using minimally invasive methods, sufficient evidence exists to demonstrate safety and efficacy of such procedures $[24,25]$.

In the present study we observed significantly less pain at day 1 after PRA as compared to LTA ( $p<$ 0.05 ) (Table II, Figure $3 \mathrm{~A}$ ). This finding is consistent with previous studies $[16,18,26]$. At least in part this can be explained by irritation of the diaphragm by pneumoperitoneum. Interestingly, the least painful was the postoperative period after right-sided PRA, with a significant difference as compared to left-sided PRA (Figure $3 \mathrm{~B}$ ). The right retroperitoneal space is separated from the left retroperitoneal space by the spine, paravertebral muscles and large abdominal vessels. Several factors have been implicated in pain sensation [27]. Pain intensity may be regulated by sphingosine-1-phosphate $[28,29]$. Also interleukin-6 is emerging as a new factor responsible for pain sensation [30, 31]. The prevalence of pain was reported to be associated with obesity, which might be due to metabolic disturbances [32-34].

Hospital stay has frequently been addressed in studies comparing LTA to PRA with shorter values for the latter group $[16,18,26]$. These observations are in line with our study's results. Interestingly, hospi- 
A

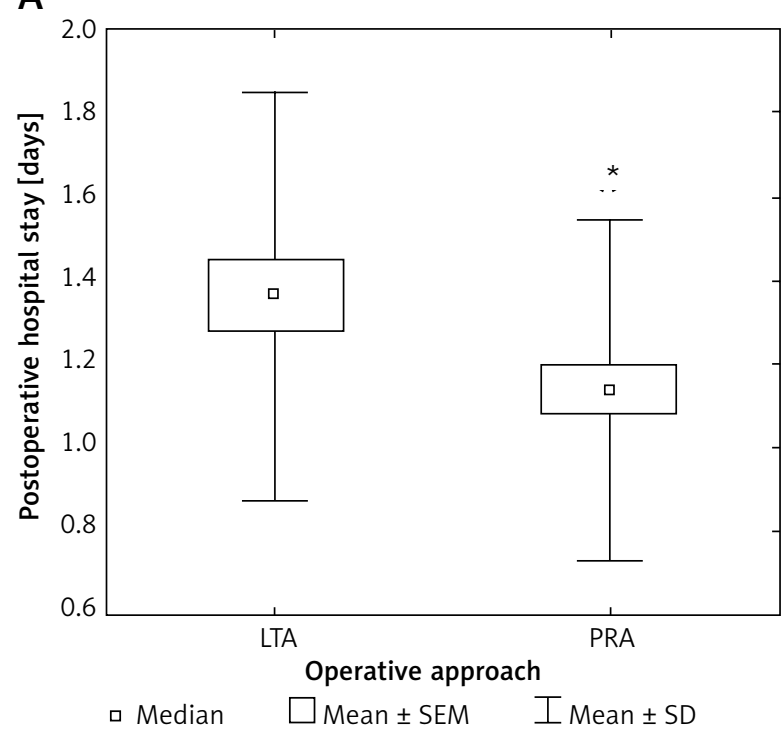

B

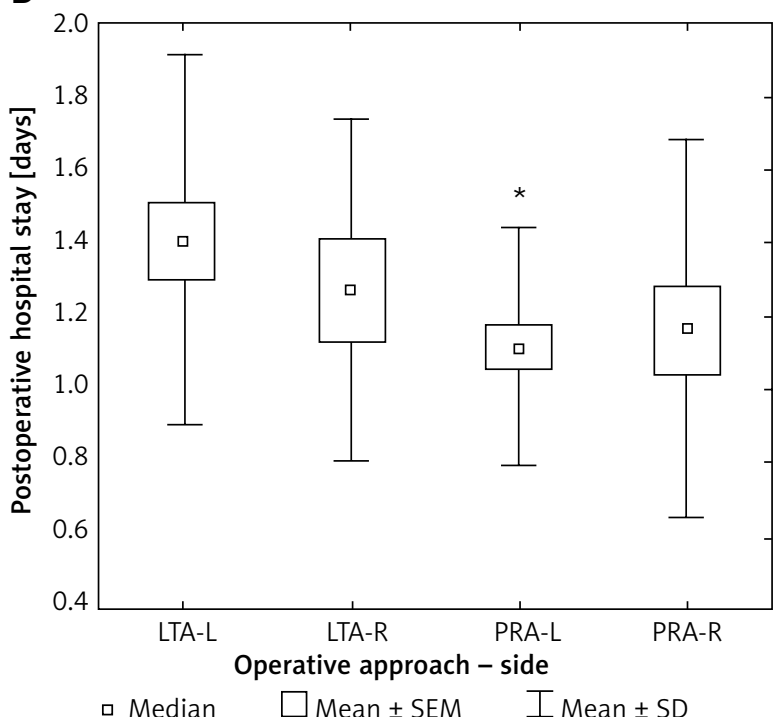

Figure 5. A - Postoperative hospital stay according to laparoscopic approach. B - Postoperative hospital stay according to laparoscopic approach and side of adrenalectomy

LTA - lateral transperitoneal approach, PRA - posterior retroperitoneal approach, SEM - standard error of measurement, SD - standard deviation; ${ }^{*} p<0.05$. LTA-L - left adrenalectomy by lateral transperitoneal approach, LTA- $R$ - right adrenalectomy by lateral transperitoneal approach, $P R A-L$ - left adrenalectomy by posterior retroperitoneal approach, PRA-R - right adrenalectomy by posterior retroperitoneal approach. Comparison to $L T A-L:{ }^{*} p<0.05$

tal stay was the shortest after left-sided PRA (Figure $5 \mathrm{~B}$ ). Possible the compression of the inferior vena cava during insufflation of $\mathrm{CO}_{2}$ under pressure of $25 \mathrm{~mm} \mathrm{Hg}$ may decrease blood flow towards the heart, which might potentially lead to temporary hemodynamic or renal dysfunction with a possible impact on hospital stay.

In this study we demonstrated that both LTA and PRA can be performed with very low morbidity. Barczyński et al. [18] described wound-related complications in 7 (22\%) patients after LTA: 4 hernias, 1 dehiscence requiring surgical treatment and 1 wound infection. We did not observe any wound-related complications. This might be due to shorter follow up (8-47 months), but also to two maneuvers we systematically perform. One is fragmentation of the specimen after it has been placed in the extraction bag with edges well outside. The second is closure of all trocar sites $10 \mathrm{~mm}$ or larger using a laparoscopic port closure device.

An intriguing, although potentially accidental observation is ischemic heart disease in 2 patients after adrenalectomy. Whether this might be related to a possible adrenal insufficiency remains to be established. Three of our patients (20, 43 and 44 months after total unilateral adrenalectomy) required hydro- cortisone supplementation. This might suggest that all subjects who underwent adrenalectomy should have their cortisol checked postoperatively.

Even though PRA is our preferred technique nowadays, we acknowledge that it is not suitable for tumors larger than $8 \mathrm{~cm}$ and it may be more difficult to learn than LTA due to the limited retroperitoneal space and different anatomical landmarks.

Our study has several limitations. The study was not blinded. Both patients and hospital staff were aware what type of operation had been performed (we found it impossible to blind the operative approach for longer than a few days). The groups were not equal in size (33 vs. 44 patients) - we knowingly decided to randomize all the patients with no respect to obtained sizes of the groups. Finally the follow-up was intermediate-term (on average 28 months in both groups), and not long-term.

\section{Conclusions}

The present study comparing LTA and PRA laparoscopic adrenalectomies confirmed the safety, efficacy and very low morbidity of both techniques. The PRA proved superior to LTA in terms of lower intensity of postoperative pain and shorter hospital stay. 


\section{Acknowledgments}

We would like to express our gratitude to prof. Marcin Barczynski for the opportunity to learn videoscopic adrenalectomy and for the supervision of our first operations.

\section{Conflict of interest}

\section{The authors declare no conflict of interest.}

\section{References}

1. Mansmann G, Lau J, Balk E, et al. The clinically inapparent adrenal mass: update in diagnosis and management. Endocr Rev 2004; 25: 309-40.

2. Swiglo BA, Murad MH, Schünemann HJ, et al. A case for clarity, consistency, and helpfulness: state-of-the-art clinical practice guidelines in endocrinology using the grading of recommendations, assessment, development, and evaluation system. J Clin Endocrinol Metab 2008; 93: 666-73.

3. Szeliga J, Sondka Z, Jackowski M, et al. NOD2/CARD15 polymorphism in patients with rectal cancer. Med Sci Monit 2008; 14 480-4.

4. Kuklinski A, Kamocki Z, Koda M, et al. IGF-IR in patients with advanced colorectal cancer in correlation with certain clinico-morphological factors: initial report. Oncol Lett 2011; 2: 1155-9.

5. Buia A, Stockhausen F, Hanisch E. Laparoscopic surgery: a qualified systematic review. World J Methodol 2015; 5: 238-54.

6. Szeliga J, Jackowski M. Minimally invasive procedures in severe acute pancreatitis treatment - assessment of benefits and possibilities of use. Videosurgery Miniinv 2014; 9: 170-8.

7. Piatkowski J, Jackowski M, Szeliga J. Laparoscopic surgery of esophageal hiatus hernia - single center experience. Videosurgery Miniinv 2014; 9: 13-7.

8. Gagner M, Lacroix A, Bolté E. Laparoscopic adrenalectomy in Cushing's syndrome and pheochromocytoma. N Engl J Med 1992; 327: 1033.

9. Hazzan D, Shiloni E, Golijanin D, et al. Laparoscopic vs open adrenalectomy for benign adrenal neoplasm. Surg Endosc 2001; 15: 1356-8.

10. Tiberio GA, Baiocchi GL, Arns L, et al. Prospective randomized comparison of laparoscopic versus open adrenalectomy for sporadic pheochromocytoma. Surg Endosc 2008; 22: 1435-9.

11. Walz MK, Alesina PF, Wenger FA, et al. Posterior retroperitoneoscopic adrenalectomy - results of 560 procedures in $520 \mathrm{pa}$ tients. Surgery 2006; 30: 899-908.

12. Lee CR, Walz MK, Park S, et al. A comparative study of the transperitoneal and posteriorior retroperitoneal approaches for laparoscopic adrenalectomy for adrenal tumors. Ann Surg Oncol 2012; 19: 2629-34.

13. Constantinides VA, Christakis I, Touska P, Palazzo FF. Systematic review and meta-analysis of retroperitoneoscopic versus laparoscopic adrenalectomy. Br J Surg 2012; 99: 1639-48.

14. Nigri G, Rosman AS, Petrucciani N, et al. Meta-analysis of trials comparing laparoscopic transperitoneal and retroperitoneal adrenalectomy. Surgery 2013; 153: 111-9.
15. Shen WT, Grogan R, Vriens M, et al. One hundred two patients with pheochromocytoma treated at a single institution since the introduction of laparoscopic adrenalectomy. Arch Surg 2010; 145: 893-7.

16. Chen W, Li F, Chen D, et al. Retroperitoneal versus transperitoneal laparoscopic adrenalectomy in adrenal tumor: a meta-analysis. Surg Laparosc Endosc Percutan Tech 2013; 23: 121-7.

17. Conzo G, Tartaglia E, Gambardella C, et al. Minimally invasive approach for adrenal lesions: systematic review of laparoscopic versus retroperitoneoscopic adrenalectomy and assessment of risk factors for complications. Int J Surg 2016; 28: S118-23.

18. Barczyński M, Konturek A, Nowak W. Randomized clinical trial of posterior retroperitoneoscopic adrenalectomy versus lateral transperitoneal laparoscopic adrenalectomy with a 5-year follow-up. Ann Surg 2014; 260: 740-7.

19. Mysliwiec P, Marek-Safiejko M, Lukaszewicz J, et al. Videoscopic adrenalectomy - when does retroperitoneal seem better? Videosurgery Miniinv 2014; 9: 226-33.

20. Fernandez-Cruz L, Saenz A, Benarroch G, et al. Laparoscopic unilateral and bilateral adrenalectomy for Cushing's syndrome. Transperitoneal and retroperitoneal approaches. Ann Surg 1996; 224: 727-36.

21. Mohammadi-Fallah MR, Mehdizadeh A, Badalzadeh A, et al. Comparison of transperitoneal versus retroperitoneal laparoscopic adrenalectomy in a prospective randomized study. J Laparoendosc Adv Surg Tech 2013; 23: 362-6.

22. Rubinstein M, Gill IS, Aron M, et al. Prospective, randomized comparison of transperitoneal versus retroperitoneal laparoscopic adrenalectomy. J Urol 2005; 174: 442-5.

23. Dindo D, Demartines N, Clavien PA. Classification of surgical complications: a new proposal with evaluation in a cohort of 6336 patients and results of a survey. Ann Surg 2004; 240: 205-13.

24. Kuczyk M, Wegener G, Jonas U. The therapeutic value of adrenalectomy in case of solitary metastatic spread originating from primary renal cell cancer. Eur Urol 2005; 48: 252-7.

25. Sarela AI, Murphy I, Coit DG, Conlon KC. Metastasis to the adrenal gland: the emerging role of laparoscopic surgery. Ann Surg Oncol 2003; 10: 1191-6.

26. Lee CR, Walz MK, Park S, et al. A comparative study of the transperitoneal and posteriorior retroperitoneal approaches for laparoscopic adrenalectomy for adrenal tumors. Ann Surg Oncol 2012; 19: 2629-34

27. Fillingim RB. Individual differences in pain: understanding the mosaic that makes pain personal. Pain 2017; 158 (Suppl 1): S11-8.

28. Doolen S, Iannitti T, Donahue RR, et al. Fingolimod reduces neuropathic pain behaviors in a mouse model of multiple sclerosis by a sphingosine-1 phosphate receptor 1-dependent inhibition of central sensitization in the dorsal horn. Pain 2018; 159: 224-38.

29. Mysliwiec H, Baran A, Harasim-Symbor E, et al. Increase in circulating sphingosine-1-phosphate and decrease in ceramide levels in psoriatic patients. Arch Dermatol Res 2017; 309: 79-86.

30. Lin Y, Liu L, Jiang $\mathrm{H}$, et al. Inhibition of interleukin-6 function attenuates the central sensitization and pain behavior induced by osteoarthritis. Eur J Pharmacol 2017; 811: 260-7.

31. Mysliwiec J, Zbucki R, Winnicka MM, et al. A crucial role of interleukin-6 in the pathogenesis of thyrotoxicosis-related dis- 
turbances of bone turnover in mice. Horm Metab Res 2007; 39: 884-8.

32. Jimenez-Trujillo I, Lopez-de-Andres A, Del Barrio J, et al. Gender differences in the prevalence and characteristics of pain in Spain: report from a population-based study. Pain Med 2019 doi: 10.1093/pm/pnz004. (Epub ahead of print).

33. Choromanska K, Choromanska B, Dabrowska E, et al. Saliva of obese patients - is it different? Postepy Hig Med Dosw 2015; 69: $1190-5$

34. Choromanska B, Mysliwiec P, Dadan J, et al. The clinical significance of fatty acid binding proteins. Postepy Hig Med Dosw 2011; 65: 759-63.

Received: 28.02.2019, accepted: 10.03.2019. 